\title{
Chinese Translation of English Advertisements under the Guidance of Skopos Theory
}

\author{
Weixuan Shi ${ }^{1}$, Wenqian $\mathrm{Li}^{2 *}$ \\ ${ }^{1}$ Professor in School of Foreign Languages, North China Electric Power University, NO 689 Road, North District, Baoding, Hebei, China \\ ${ }^{2}$ Graduate Student in School of Foreign Languages, North China Electric Power University, NO 689 Road, North District, Baoding, Hebei, China
}

DOI: $10.36348 /$ SJHSS.2019.v04i09.002

| Received: 02.09.2019 | Accepted: 09.09.2019| Published: 20.09.2019

*Corresponding author: Wenqian $\mathrm{Li}$

Abstract

With the rapid development of information technology and the huge business opportunities brought by China's entry into the World Trade Organization (WTO), English advertisements are increasingly teemed with daily life. Therefore, the internationalization and globalization of advertisements has become an indispensable portion of people's lives. Among them, the Chinese translation of English advertisements is becoming more and more important. The translation of English advertisements that is in line with aesthetic habits of Chinese readers can considerably boost the effect of publicity and effectively promote the sales of products. Based on the Skopos theory, this article analyzes several translation strategies of English advertisement through specific examples from the perspective of the uniqueness of English advertisement. It provides a theoretical basis for the translators to flexibly employ translation strategies in commercial English advertisements. And it has the vital guiding significance for advertisers to successfully attract consumers and achieve the purpose of advertising by the optimal translation.

Keywords: English advertisements, Skopos theory, translation strategy.

Copyright @ 2019: This is an open-access article distributed under the terms of the Creative Commons Attribution license which permits unrestricted use, distribution, and reproduction in any medium for non-commercial use (NonCommercial, or CC-BY-NC) provided the original author and source are credited.

\section{INTRODUCTION}

As the exchanges between China and foreign countries are more and more frequent, advertisements as a way of disseminating information have become an indispensable part of people's life. The Chinese translation of English advertisements is particularly crucial. Advertisement translation is not only closely relevant to product sales, reputation and economic benefits, but also reflects the cultural quality of a country or a nation to some extent [1]. In addition, advertisers can promote products with superior advertisement translation, which is relatively a good approach to distinguish their products from others. Whoever is more ingenious in translation will win more consumers. Therefore, the success of advertisements is determined by whether advertisers can masterly use advertisement translation to attract consumers, thus expanding brand awareness considerably.

However, "Advertisement translation has not been well-regulated for a long time. Until just recently, some scholars have explored advertisement translation from the perspective of linguistics or cultural communication" [2]. In the investigation of the status quo of advertisement translation in China, Hao Shuanhu
[3] found that the theoretical level of advertisement translation in China needs to be strengthened, which indicates that it is imperative for studies with theoretical guidance to fill the gap in advertisement translation. The Skopos theory, put forward by Vermeer in the 1970s, provides active guidance for translation studies, especially translation of practical writings, on account of its emphasis on the purpose and function of translation, and its effect on expanding the scope of translation studies. This theory provides a theoretical basis for the translation of advertisements, which is a kind of practical writings with the prominent purpose. Accordingly, it is of great practical significance and practical value to study the translation strategies of English advertisements under the guidance of Skopos theory.

\section{Skopos Theory}

In the 1970s, Hans Vermeer [4] in Germany proposed the Skopos theory, the foundational theory in German functionalist translation theory, in his book Ordinary Translation Theory Framework. Vermeer believes that many of the problems in translation cannot be resolved by linguistics alone, and the most important element that determines the translation process is the 
purpose of the overall translation behavior. Completely different from the traditional "equivalent view", the Skopos theory does not lay emphasis on whether the translation is equivalent to the original text. Instead, the Skopos theory stresses that the translator takes the expected function of the translation as the starting point in the translation process, and selects the optimum method according to various context factors [5]. In translation, the original text is not a measure standard of all. In other words, the faithfulness of the original text is secondary, while the purpose of translation is primary.

After clarifying the translation task, three principles should be abided by in translation practice. Firstly, "Skopos rule" means that the purpose of translation determines the whole process of translation. Secondly, "coherence rule" denotes that translation must be understandable to the reader and meaningful in the context of the target language culture. The third principle is the "fidelity rule", which emphasizes that intertextual coherence should exist between the original text and the translation text, that is, the so-called faithfulness to the original text. Meanwhile, the degree of fidelity is determined by the purpose of the translation and the translator's comprehension of the original text. Among these three principles, when the fidelity rule conflicts with the standard of functionalism, it is subject to the coherence rule, and both of rules are subject to the Skopos rule [6]. That is to say, the first principle that translators are bound to follow is the "Skopos rule". On the basis of Skopos theory, the purpose of translation is the most critical factor of translation. In order to achieve translation purposes, the translator can exploit any feasible strategies. This is the true essence of Skopos theory.

Advertising is a sort of business activity with specific purposes and is goal-oriented. The principal purpose of advertisements is to convey products' information and to attract consumers' attention, thus winning customers and facilitating their purchase activities. Owing to the fact that consumers have different backgrounds in politics, economy, culture, etc., it is inevitable that translators need to make some changes in the translation process in order to enable consumers to understand and accept the promoting products [7]. Hence, the Skopos theory, which takes the principle of purpose as the first rule, has a strong guiding effect on advertisement translation. It can guide translators to adopt appropriate methods in the translation of English advertisements to achieve the anticipated purpose.

\section{Translation strategies of English advertisements based on Skopos Theory}

Skopos theory holds that the original text only plays the role of "offer of information". The translator should effectively process the original information on the ground of translation requirements. It is possible for the translator to retain, or change, or delete, or add, so as to make the translation achieve its intended purpose. For advertisement translation, the purpose of translation is to publicize goods, persuade customers and stimulate consumption. Strategies of advertisement translation are flexible and diverse, and the common translation methods are as follows.

\section{Literal Translation}

The literal translation method preserves the language structure of the original text as much as possible without destroying the meaning and the communicative function of the original text. Languages have something in common. With literal translation, we can retain the uniqueness of the original advertisement to the utmost extent, converting the grammatical structure of the original language into the corresponding structure in the target language.

\section{Example 1 Obey your thirst.}

This simple sentence uses the short verb “obey". Short verbs are widely used in people's daily life and possess the most explicit meaning, making the advertisements concise and vivid. Besides, this advertising slogan is an imperative sentence. Imperative sentences have strong persuasiveness and appeal, so they appear frequent in advertisements. The use of imperative sentences is to make requests to consumers, affect and stimulate consuming behavior of readers. In this English advertisement "Obey your thirst", its purpose is to simply and directly stimulate consumers' desire to purchase the product Sprite soda. The literal translation of “服从你的渴望” abides by the “fidelity rule" and "Skopos rule", which can clearly convey the message and achieve the same effect as the original English advertisement.

Example 2 Impossible made possible.

This English slogan applies the rhetoric of oxymoron, which is to use two obviously contradictory words together to produce the rhetorical effect of the epigram. Such sentences seem to be contradictory from the appearance; however, in fact they have profound meanings and implications. This advertising slogan "Impossible made possible" puts together two words "impossible" and "possible", which poles apart. The contrast between these two words is distinct and vivid, which fully demonstrates the excellent quality of Canon printers. The purpose of this advertisement is to attract readers' attention through such contradictory effects and highlight the superior quality of the products. In line with the "fidelity rule" and "Skopos rule", translating this English advertisement directly and literally into “使不可能变为可能” achieves the same effect.

\section{Linear Translation}

The linear translation method refers to the adjustment of the original language structure in accordance with the characteristics of the target 
language on the premise of grasping the meaning of the original text, so that it conforms to the expression habits of the target language [8]. After all, Chinese and English are two different languages. If we utilize the literal translation strategy, the Chinese translation cannot be faithful to the original English text, nor can't the reader accept and understand it. Then it is necessary to follow the "coherence rule" to find the appropriate expressions in Chinese culture. Only in this way, can the purpose of translation be achieved and can Chinese readers fully understand.

Example 3 Time is what you make of it.

By using the rhetoric of hyperbole, this English advertisement is vivid and powerful. This advertisement is distinctive salient, because the use of hyperbole strengthens the language effect and adds a little literary flavor to the advertisement, which turns it into a catchy and fascinating slogan. The literal translation of “时间是由你创造的” cannot show the Swatch's durability, and cannot achieve good promotional effect. Therefore, for a better translation, we can first change the order of the original sentence to "You make of time", and extract the underlying goal of advertisement -promoting the watch's durability. Then we can comply with the "coherence rule", select four words commonly used in Chinese and translate it as "天 长地久”. This Chinese translation not only successfully conveys the superior quality of the product, but also caters to the "eternity" advocated by the Chinese consumers, which makes Chinese people feel at home.

Example 4 Maxwell: Good to the last drop.

As the world's second largest coffee brand, Maxwell promotes its product by "Good to the last drop". Obviously, this English sentence is a simple one with the evaluative adjective "good". In English advertisements, the most frequently used words are adjectives, most of which are evaluative adjectives. These words are endowed with a riot of emotional colors. In China, the translation of “滴滴香浓, 意犹未 尽” is very popular and classic. Compared with Nestle (Nestle: The taste is great!), Maxwell's“香浓”is more prominent. Although the translation of Maxwell's slogan is not as direct as Nestle, it is in line with relaxed mood when tasting coffee. The phrase “意犹未尽 "cleverly captures the characteristics of Chinese consumers' image thinking, and combines the mellowness of coffee with the consumers' inner feelings. Accordingly, this Chinese translation follows both "Skopos rule" and "coherence rule", employing the linear translation method, and can be accepted and understood by the Chinese reader. Even after 50 years of vicissitudes, this Chinese slogan is still unique in the Chinese market.

\section{Corresponding Translation}

The corresponding translation strategy refers to applying the fixed expressions in the target language, which can be the ready-made advertisements, or can be a proverb, an idiom, a verse, a lyric, and the like. This approach accords with "coherence rule" in the Skopos theory; hence, consumers can have a feeling of having met the advertisement before, and they are apt to keep the product in mind.

\section{Example 5 Tasting is believing.}

This is an English advertisement about food, and it is a simple sentence. Superb simple sentences often state important facts and opinions. They are powerful and accurate, expressing explicit content in a few words. Therefore, English advertisements rarely use compound sentences but simple sentences instead. This English advertisement "Tasting is believing" is borrowed from"Seeing is believing". And the Chinese translation can also be borrowed from the Chinese proverb “百闻不如一见”, and altered into “百闻不如 一尝”, which not only makes people eager to try, but also implies that the food is of great quality.

Example 6 The only thing we did not improve was the road.

This is an English advertisement for a Japanese car. It means that the car is perfect and the only thing that needs to be improved is the road, which vividly highlights the quality of the car by the use of hyperbole. To accomplish the translation purpose, this English advertisement can be translated as “万事俱备 ，只欠路况” as per the request of “coherence rule”, which borrows from“万事俱备，只欠东风”. Strictly speaking, this Chinese translation not only emphasizes the effect of the product, but also reads catchy and melodic, which shortens the distance between the product and Chinese consumers and endows the product with vitality, emotion and credibility.

\section{Amplification in Translation}

Amplification in translation means that in order to express the purpose of advertisements more clearly, by digging into the deep meaning of the original text or filling in the necessary cultural information, the translation is more consistent with the expression of the target language. As a matter of fact, this translation strategy abides by both "coherence rule" and "fidelity rule", thus expressing the deep meaning of the original text more accurately.

\section{Example 7 A diamond is forever.}

This English slogan for the De Beers' diamonds applies the figurative rhetoric, which enhances the beauty of the language. In English advertisements, advertisers often exert their rich imagination to replace the propaganda products with a beautiful thing, turn the abstract into the concrete, so that the slogan is refined and vivid, enhancing the 
beauty of language. Diamonds represent eternity and advertisers want to promote the beauty of diamonds through this English slogan. “钻石恒久远, 一颗永流 传。” is the widespread Chinese translation of the advertising slogan. If we translate this slogan literally as“钻石恒久远”, we cannot display the uniqueness of De Beers' diamonds so that the purpose of propagating the goods cannot be fully realized despite the fact that we strictly comply with the original text. Therefore, it is very necessary to add“一颗永流传”.

Example 8 Nourishes skin with the moisture it needs or a softer, more healthy appearance.

This English advertisement singles out the evaluative adjective "softer" and "more healthy". The comparative and superlative adjectives are also frequently used in English advertisement to show the merits of this product superior to other products. The Chinese translation is“雅芳保湿营养霜蕴涵丰富维生 素和天然保湿成分, 具滋养和保湿功效。为肌肤提 供氧分和水分, 另肌肤全日滋润亮泽、平滑柔软, 保持健康的动人光彩。[9] “雅芳保湿营养霜蕴涵丰 富维生素和天然保湿成分, 具滋养和保湿功效” is the information supplemented by the translation according to "coherence rule". It fully expresses the meaning of the advertisement and highlights the advantages of the emollient, allowing readers to fully understand the product. The translation gives a sense of conciseness and purity in both language and form, and the words between the lines reveal the beauty that nutrition cream brings to women, emotionally impressing readers and stimulating purchase desire of readers.

\section{Condensation in Translation}

Condensation in translation points out that for the consideration of culture and style, it is feasible to compress and delete the information in the original text that is invalid or not conducive to advertisements. In this case, the translation is concise and clear without redundant and cumbersome information, and it is more in line with the expression of the target language, which can be accepted and understood by the reader.

Example 9 Your lips will know it. But your hips won't show it.

The English advertisement for this Musketeers chocolate uses colloquial words and sentences, bringing consumers and advertisers closer together. Colloquial words are expressive, easy to understand, and can achieve good results. The English advertisement can be translated as“您的嘴唇感觉到, 您的屁股不显现 ”and“好吃看不见”. Complying with the “fidelity rule”, “您的嘴唇感觉到, 您的屁股不显现”is translated literally, retaining the original meaning and the "form" of the original text. Although the literal translation conveys the message of the original text, it does not convey the meaning of the original advertisement very well, and it does not seem elegant to read. “好吃看不见” breaks through the external form of the original advertisement in the light of "coherence rule" and "Skopos rule", reflecting the feature that the chocolate is both "good" and "cannot make people fat". Simplified and concise, easy to be remembered and accepted by consumers, it can play a good publicity effect of advertising.

Example 10 Wherever you are. Whatever you do. The Allianz Group is on your side.

It is apparent that this English advertisement also uses colloquial expressions, and words and sentences are relatively simple. The English sentences feature in strong sense of reality, making readers clear at the first glance. If we translate it literally and directly, it is“无论你在哪，无论你在做什么，安联集 团，永远在你身边”. This literal translation appears redundant to some degree and it is too long enough for the reader to achieve good results. The condensation“安 联集团，永远在你身边”compresses the invalid information in the original text and conforms to the Chinese language habits.

\section{CONCLUSION}

In summary, advertising is a competitive business behavior, with the purpose to strive for consumers; therefore, it must put the consumer as the consuming center, cater to their pleasure, and stimulate their purchase. Accordingly, English advertisement in the wording and rhetoric aspect has its own uniqueness, while the translation of the advertisement puts more emphasize on the effect. If the advertisement is translated into another language word by word mechanically, it may not be able to achieve the original effect. Therefore, in the process of translation, what should be stressed is that we need to follow the three principles in Skopos theory and ascertain the purpose of advertisement. According to the content and characteristics of the advertisements, coupled with the characteristics of the products, translators should modestly select the appropriate translation strategies and translate English advertisements into Chinese version that will meet the reader's aesthetic needs. Not only can this way of translation show the writing style of the original text, but also comprehensively and flexibly express the complete original information, so that the Chinese readers can obtain the same feeling and the sale of products can be promoted as well.

\section{REFERENCES}

1. Weiguo, T. (2003). Rhetoric Translation of English and Chinese. Chinese Translation, 3(4), 67-69.

2. Kexing, L. (2010). Advertisement Translation Theory and Practice. Beijing: Peking University Press.

3. Shuanhu, H. (2012) Advertisement translation research status and prospects in China. Foreign Trade and Economics, 4(2), 20-23. 
4. Vermeer, H. (1978). A Framework for a General Theory of Translation. Heidelberg: Heidelberg Universiy.

5. Jeremy, M. (2010). Introducing Translation Studies: Theories and Applications. Shanghai: Shanghai Foreign Language Education Press.

6. Zheng, L. (2013). Research on Advertisement Translation from the Perspective of Skopos Theory. Foreign Languages Research, 5(8): 119120.
7. Smith, K. (2009). The Translation of Advertisement Texts. Saarbrucken: VDM Verlag Press.

8. Gang, L. (2013). Language Features and Translation Strategies of Business Advertisement English. World Book Publishing House, 3(1), 12 14.

9. Yuqi, Z., \& Yanhong, G. (2005). On the aesthetic translation advertisement of English cosmetic manuals. Chinese Translation, 3(2): 72-74. 